\title{
Synthesis and Optical properties of $\mathrm{Eu}^{3+}$ doped $\mathrm{Sr}_{2} \mathrm{SiO}_{4}$ Phosphor for Solid State lighting applications
}

\author{
${ }^{*}$ Chaudhari Dilip B. ${ }^{1}$, Zambare Pradip Z. ${ }^{2}$ and Mahajan O. H. ${ }^{3}$ \\ ${ }^{1}$ Department of Physics, ASC College, Bhalod, Dist Jalgaon, India. \\ ${ }^{2}$ Department of Physics, S. V. S's Dadasaheb Rawal College, Dondaicha, Dist: Dhule (M. S.), \\ India. \\ ${ }^{3}$ Department of Physics, M. J. College Jalgaon, (M.S.), India. \\ Corresponding Author: Chaudhari Dilip B
}

\begin{abstract}
Eu}^{3+}$ doped $\mathrm{Sr}_{2} \mathrm{SiO}_{4}$ phosphors were prepared by high temperature solid state diffusion method. The starting materials Strontium carbonate $\mathrm{SrCO}_{3}$ and silicate $\mathrm{SiO}_{3}$ are used to prepare $\mathrm{Sr}_{2} \mathrm{SiO}_{4}$ Phosphor TG/DTA and XRD analysis suggest a direct reaction between $\mathrm{SrCO}_{3}$ and $\mathrm{SiO}_{2}$ powders. The crystallite size of powders samples were calculated from X-ray peak broadening of the diffraction using Scherer's formula. The calculated average crystallite size of the $\mathrm{Sr}_{2} \mathrm{SiO}_{4}$ phosphor is $22 \mathrm{~nm}$. The XRD patterns of the powders revealed that the structure of $\mathrm{Sr}_{2} \mathrm{SiO}_{4}$ is orthorhombic. The photoluminescence of the obtained phosphors were studied. The conversion ratios of the $\mathrm{Sr}_{2} \mathrm{SiO}_{4}$ starting materials are calculated from the weight loss. X-ray diffraction analysis shows single phase products after annealing temperature $>900{ }^{\circ} \mathrm{C}$. The CIE co-ordinates for the Eu, doped $\mathrm{Sr}_{2} \mathrm{SiO}_{4}$ phosphors were $x=0.64$ and $y=0.33$. From the CIE chromaticity diagram for the emissions of pure and $\mathrm{Eu}^{3+}$ doped $\mathrm{Sr}_{2} \mathrm{SiO}_{4}$. This phosphor having color tenability from blue to white light and this phosphor has an important candidate of the lighting system.
\end{abstract}

Keywords: $\mathrm{Sr}_{2} \mathrm{SiO}_{4}$, solid state diffusion method, SEM, Phosphor.

\section{Introduction}

Phosphor materials are essential due to their emerging expertise with solid state lighting (SSL), SSL is the recent revolution in the lighting technology, wherein the low power light emitting diodes (LEDs) are used for lighting applications. Research on down conversion phosphor materials is key for the development of SSL [1]. Alkaline earth silicate is a important luminescent material because of its outstanding chemistry and thermal stabilization, facile synthesis and cheap raw material $\left(\mathrm{SiO}_{2}\right)$, so it has been widely applied in phosphor for lamp. Since it can be excited efficiently by LED chips, there have been many reported about this material applied in phosphor for white LED [2-4]. However, it has problems of low color stability with increasing applied current, low color rendering index, and low color reproducibility [5,6]. Another new type of phosphor- $\mathrm{Sr}_{2} \mathrm{SiO}_{4}: \mathrm{Eu}^{2+}$ has attracted researchers' attention [7-9]. $\mathrm{Sr}_{2} \mathrm{SiO}_{4}$ provides the broadband absorption in UV/Blue region due to low symmetry of the crystallographic sites. In addition, the $\mathrm{Sr}_{2} \mathrm{SiO}_{4}: \mathrm{Eu}^{2+}$ phosphor has a higher luminous efficiency, CRI and color stability than YAG [10,11], and giving rise to a new phosphor approach for white LED applications.

The synthesis by solid state reaction method is very easy and does not require expensive as well as sophisticated equipments. The main advantage of solid state reaction method is, the ending production solid form is structurally pure with the desired properties depending on the final sintering temperatures. This technique is environment friendly and no toxic or unwanted waste is produced after the solid state reaction is complete. In this method the powders produced from solid state reaction is very fine as well as the cross contamination is very less. [12].

$\mathrm{Sr}_{2} \mathrm{SiO}_{4}$ is a suitable host lattice for phosphor applications $\mathrm{Sr}_{2} \mathrm{SiO}_{4}$ powder is usually prepared in a solid-state reaction by heating mixed strontium and silicon salts at elevated temperatures. Knowledge of the fundamental reaction kinetics and mechanism are important when optimizing the solid-state process for phosphor applications. In this study, $\mathrm{Sr}_{2} \mathrm{SiO}_{4}$ powders were prepared via solid-state reaction by heating mixed precursors at elevated temperatures. The purpose of this study is to explain the reaction mechanism and reaction kinetics of formation of $\mathrm{Sr}_{2} \mathrm{SiO}_{4}$ in a solid-state reaction. The precursors were examined using thermal and $\mathrm{X}$ ray diffraction analysis to determine the optimum reaction range. The isothermal analysis was adopted to understand the reaction mechanism and kinetics. Using the microstructural observations accompanied by the kinetics, a reaction model for the formation of $\mathrm{Sr}_{2} \mathrm{SiO}_{4}$ via the solid-state reaction is proposed. 


\section{Experimental Methods And Materials}

$\mathrm{Sr}_{2} \mathrm{SiO}_{4}$ phosphor was synthesized by the solid state reaction method. Strontium carbonate $\left(\mathrm{SrCO}_{3}\right.$, Aldrich Chemicals, 99.9\%), and silicon dioxide $\left(\mathrm{SiO}_{2}\right.$, Aldrich Chemicals, 99.6\%) were mixed in their stoichiometric ratio according to the $\mathrm{Sr}_{2} \mathrm{SiO}_{4}$ chemical formula. A Stoichiometric mixture of these powders was thoroughly homogenized in agate mortar for $1 \mathrm{hr}$. and then transferred to alumina crucibles. The homogenized mixture was heated in air at $1200{ }^{\circ} \mathrm{C}$ for $4 \mathrm{~h}$ in a muffle furnace with heating rate of $300{ }^{\circ} \mathrm{C} / \mathrm{hr}$. Finally cool down to room temperature by furnace shut off. All samples were prepared by same technique.

Thermo gravimetric analysis (TG, DTA) of precursor of $\mathrm{Sr}_{2} \mathrm{SiO}_{4}$ was carried out in nitrogen atmosphere in 30-12000 C temperature range using a Perkin Elmer, Diamond TG/DTA instrument. The initial mass of sample taken for recording the TG/DTA curves was $64.778 \mathrm{mg}$ and hold for $1.0 \mathrm{~min}$ at $300 \mathrm{C}$, and then heating rate was maintained at $100 \mathrm{C} / \mathrm{min}$. The phase composition and phase structure were characterized by Xray diffractograms (XRD) using an automated Rigaku Miniflex X- ray diffractometer (D Max III VC, Japan). The photoluminescence excitation and emission spectra were measured by Spectrofluorophotometer (SHIMADZU, RF - 5301 PC) equipped with a $150 \mathrm{~W}$ Xenon lamp as excitation source.

\section{Results And Discussion}

Fig $1 \mathrm{a}$ ) and b) illustrates the DTA and TGA curves for the $\mathrm{Sr}_{2} \mathrm{SiO}_{4}$ precursors heated at rate of $10{ }^{\circ} \mathrm{C} /$ min. The TG-DTA analysis showed two stages of weight loss accompanied by two endothermic peaks. The corresponding endothermic peak at 100 and $450{ }^{\circ} \mathrm{C}$ in DTA curve, corresponding to the weight loss shown in TG, was due to precursor dehydration. An apparent weight loss occurred at around $700{ }^{\circ} \mathrm{C}$, and no further weight loss was found at temperatures higher than $980{ }^{\circ} \mathrm{C}$. To explain the broad endothermic peak at around 820 ${ }^{\circ} \mathrm{C}$, the DTA/TG analysis for pure strontium carbonate and silicon dioxide ( $\left.\mathrm{SiO} 2\right)$ were also performed. According to our experimental results, the silicon dioxide seemed to be stable in comparison with strontium carbonate in the range of $25^{\circ} \mathrm{C}$ to $1000^{\circ} \mathrm{C}$.
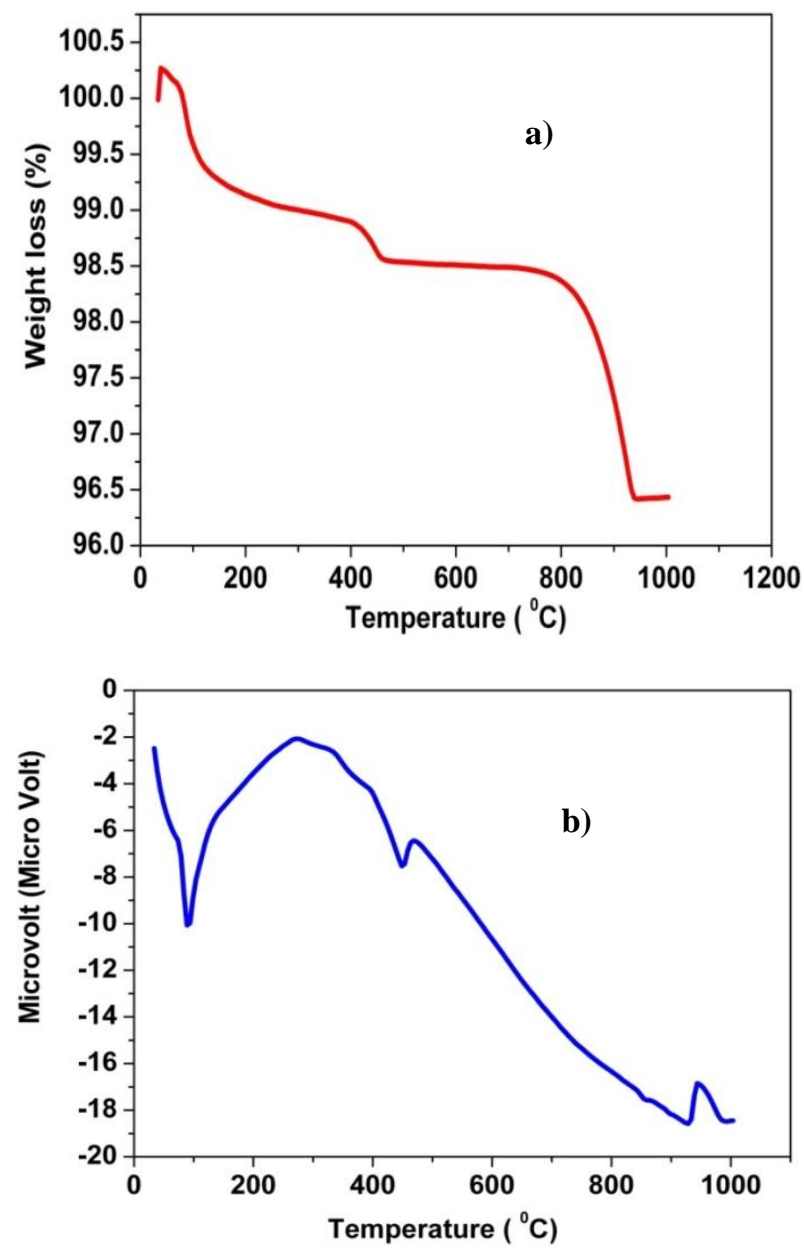

Fig. 1 a) and b) shows TG and DTA of Precursor of $\mathrm{Sr}_{2} \mathrm{SiO}_{4}$.

As a result, the endothermic peak at $820{ }^{\circ} \mathrm{C}$ shown in Fig. 1 was attributed to reactive strontium carbonate reacting with stable silicon oxide, thereby leading to the formation of $\mathrm{Sr}_{2} \mathrm{SiO}_{4}$. The total weight loss 
measured from TG experiment amounted to $24.7 \%$, which was closed to the theoretical weight loss of this reaction. The net equation of the reaction involving $\mathrm{SrCO}_{3}$ and $\mathrm{SiO}_{2}$ is

$$
2 \mathrm{SrCO}_{3}+\mathrm{SiO}_{2} \rightarrow \mathrm{Sr}_{2} \mathrm{SiO}_{4}+2 \mathrm{CO}_{2}
$$

The reaction was nearly completed at $1000 \circ \mathrm{C}$ after $60 \mathrm{~min}$. In addition, it was noted that for the same reaction period, the conversion increased with a rise in the heating temperature. Heating specimens at $700{ }^{\circ} \mathrm{C}$ for $120 \mathrm{~min}$ increased conversion ratio to about $71 \%$. After reacting for $120 \mathrm{~min}$, the conversion ratios at $750 \circ \mathrm{C}$ and $1000{ }^{\circ} \mathrm{C}$ were $95 \%$ and $97 \%$, respectively. The structure and phase purity of the synthesized $\mathrm{Sr}_{2} \mathrm{CeO}_{4}$ phosphor was investigated by X-Ray Diffraction Method. Results are shown in Fig. 2

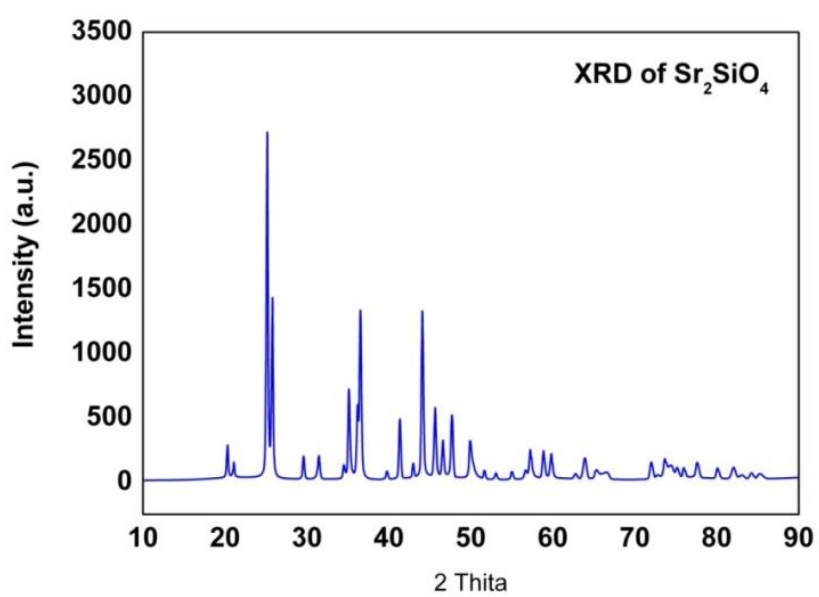

Fig. 2 XRD of $\mathrm{Sr}_{2} \mathrm{SiO}_{4}$ at temperature $1200{ }^{\circ} \mathrm{C}$.

All diffraction patterns were obtained using $\mathrm{Cu} \mathrm{K \alpha}$ radiation $\left(\lambda=1.54051 \mathrm{~A}^{\circ}\right)$, at $30 \mathrm{kV}$ and $15 \mathrm{~mA}$. Measurements were made from $2 \theta=10^{\circ}$ to $80^{\circ}$ with steps of $0.02^{\circ}$. The crystallite size of powders samples were calculated from X-ray peak broadening of the diffraction using Scherer's formula. The calculated average crystallite size of the $\mathrm{Sr}_{2} \mathrm{SiO}_{4}$ phosphor is $22 \mathrm{~nm}$. The XRD patterns of the powders revealed that the structure of $\mathrm{Sr}_{2} \mathrm{SiO}_{4}$ is orthorhombic, and it is matched with standard JCPDS data card No. 39-1256.

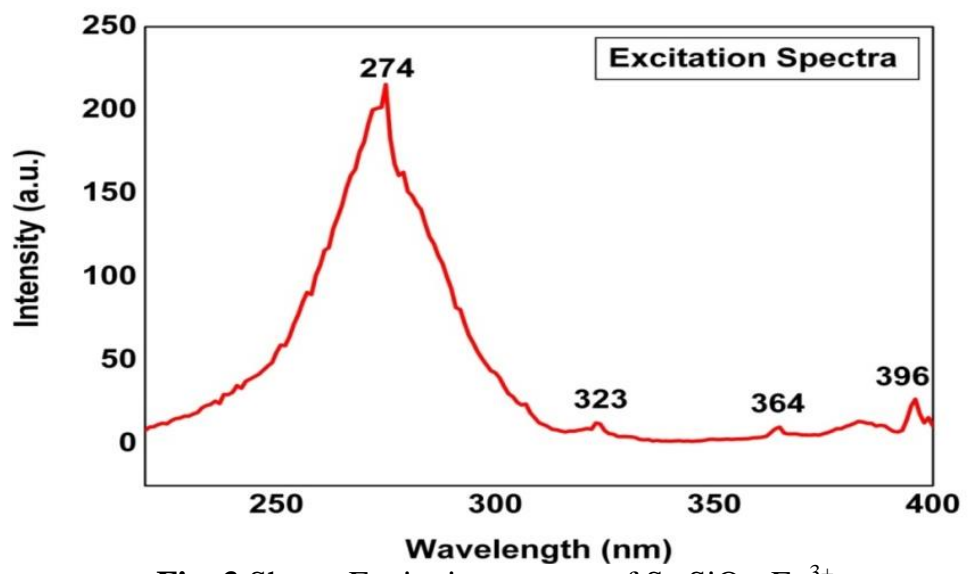

Fig. 3 Shows Excitation spectra of $\mathrm{Sr}_{2} \mathrm{SiO}_{4}: \mathrm{Eu}^{3+}$

The excitation spectra, monitored at $468 \mathrm{~nm}$ excitation peak is located around $274 \mathrm{~nm}$ is due to charge transfer band between $\mathrm{O}_{2-}-\mathrm{Eu}^{3+}$. The electron transfers to partially filled $4 \mathrm{f}$ orbit of $\mathrm{Eu}^{3+}$ from $2 \mathrm{p}$ full orbit. This transfer leads to oxidation of $\mathrm{O}_{2}$ - to $\mathrm{O}$ - and reduction of $\mathrm{Eu}^{3+}$ to $\mathrm{Eu}^{2+}$. Thus the phosphor can be efficiently excited by mercury lamp [13]. Peaks at 323,364 , and at $396 \mathrm{~nm}$ are due to ${ }^{7} \mathrm{~F}_{0} \rightarrow{ }^{5} \mathrm{G}_{2},{ }^{7} \mathrm{~F}_{0} \rightarrow{ }^{5} \mathrm{G}_{5}$ and ${ }^{7} \mathrm{~F}_{0} \rightarrow{ }^{5} \mathrm{G}_{6}$ respectively as shown in fig. 3. In $\mathrm{Eu}^{3+}$ there are two types of excitation charge transfer band and $4 \mathrm{f}-4 \mathrm{f}$ transition. The filled ${ }^{5} \mathrm{~S}_{2}$ and ${ }^{5} \mathrm{P}_{6}$ orbital shield the $4 \mathrm{f}$ orbital. Thus the influence on the optical transition by host lattice within the $4 \mathrm{fn}$ configuration is small and $4 \mathrm{f}-4 \mathrm{f}$ transition is sharp lines [14]. The emission spectra of Sr2SiO4: $\mathrm{Eu}^{3+}$ phosphor is shown in fig. 4 . Under the excitation of $256 \mathrm{~nm}$, the emission spectrum exhibits ${ }^{5} \mathrm{D}_{0}$ $\rightarrow{ }^{7} \mathrm{~F}_{\mathrm{j}}(\mathrm{j}=1,2,3,4 \ldots)$ Major peaks are observed in red region. 


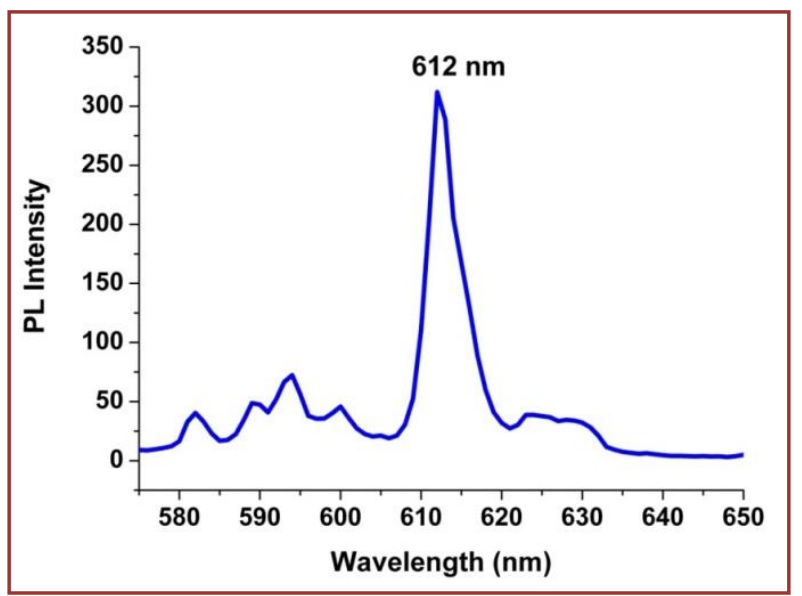

Fig. 4 Shows Emission spectra of $\mathrm{Sr}_{2} \mathrm{SiO}_{4}: \mathrm{Eu}^{3+}$

The emission peaks at 589-593, 613-619 nm are due to radiative transitions from ${ }^{5} \mathrm{D}_{0} \rightarrow{ }^{7} \mathrm{~F}_{1},{ }^{5} \mathrm{D}_{0} \rightarrow{ }^{7} \mathrm{~F}_{2}$, ${ }^{5} \mathrm{D}_{0} \rightarrow{ }^{7} \mathrm{~F}_{4}$. It may be speculated that both couples (593 and $612 \mathrm{~nm}$ ) corresponds to the $\mathrm{Eu}^{3+}$ emission [14]. The couple arises due to ${ }^{5} \mathrm{D}_{0} \rightarrow{ }^{7} \mathrm{~F}_{2}$ transition level at $393 \mathrm{~nm}$ characteristic excitation of $\mathrm{Eu}^{3+}$ ion. Eu ${ }^{3+}$ ion substitutes $\mathrm{Sr}^{2+}$ ions in the host lattice which may lead to emission at 593 and $613 \mathrm{~nm}$ The broad emission spectrum occurs at $612 \mathrm{~nm}$ due to transition ${ }^{5} \mathrm{D}_{0} \rightarrow{ }^{7} \mathrm{~F}_{4}$.

Most lighting specifications refer to colour in terms of the 1931 CIE chromatic colour coordinates which recognize that the human visual system uses three primary colours: red, green, and blue. In general, the colour of any light source can be represented on the (x,y) coordinate in this colour space. The colour purity was compared to the 1931 CIE Standard Source C (illuminant $C$ s $(0.3101,0.3162)$ ). The dominant wavelength is the single monochromatic wavelength that appears to have the same colour as the light source. The dominant wavelength can be determined by drawing a straight line from one of the CIE white illuminants $(C \mathrm{~s}$ ( 0.3101 , $0.3162)$ ), through the (x,y) coordinates to be measured, until the line intersects the outer locus of points along the spectral edge of the 1931 CIE chromatic diagram [15-18].

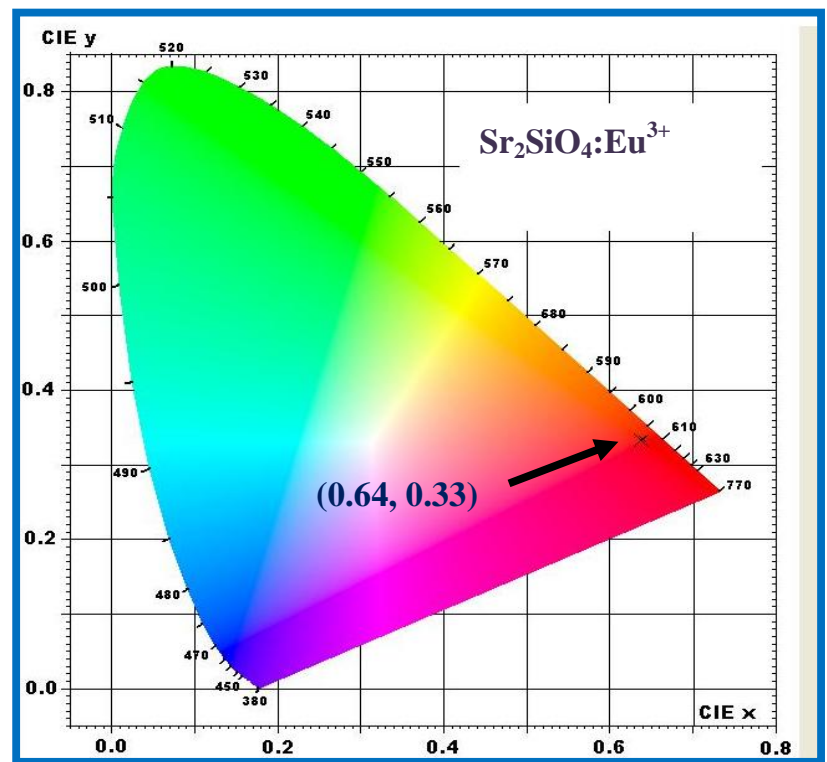

Fig. 5. CIE for $2.0 \mathrm{~mol} \% \mathrm{Eu}^{3+}$ doped $\mathrm{Sr}_{2} \mathrm{SiO}_{4}$ phosphor.

The CIE co-ordinates for the Eu, doped $\mathrm{Sr}_{2} \mathrm{SiO}_{4}$ phosphors were $\mathrm{x}=0.64$ and $\mathrm{y}=0.33 \mathrm{Fig}$. 5. Illustrates the CIE chromaticity diagram for the emissions of pure and Eu3+, (2.0 mol \%) doped $\mathrm{Sr}_{2} \mathrm{SiO}_{4}$. This phosphor having colour tenability from blue to white light and this phosphor has potential of an application in the lighting system

Table 1 CIE coordinates for $\mathrm{Sr}_{2} \mathrm{SiO}_{4}: 1.0 \% \mathrm{Eu}^{3+}$

\begin{tabular}{c|cccc}
\hline Phosphor & $\begin{array}{c}\text { Excitation } \\
(\mathrm{nm})\end{array}$ & $\begin{array}{c}\text { Strong Emission } \\
(\mathrm{nm})\end{array}$ & $(\mathrm{x}, \mathrm{y})$ Coordinate & Color region \\
\hline $\mathrm{Sr}_{2} \mathrm{SiO}_{4}: 1.0 \% \mathrm{Eu}^{3+}$ & 256 & 612 & $(0.64,0.33)$ & Orange Red \\
\hline
\end{tabular}




\section{Conclusions}

$\mathrm{The}_{\mathrm{Sr}} \mathrm{SiO}_{4}: \mathrm{Eu}^{3+}$ phosphor has been synthesized by the high temperature solid state diffusion method. The reaction mechanism and kinetic analysis for the formation of $\mathrm{Sr}_{2} \mathrm{SiO}_{4}$ are investigated in this study. The process of formation of $\mathrm{Sr}_{2} \mathrm{SiO}_{4}$ is assumed to be a direct reaction between $\mathrm{SrCO}_{3}$ and $\mathrm{SiO}_{2}$ via the TG/DTA and XRD analysis. The conversion of $\mathrm{Sr}_{2} \mathrm{SiO}_{4}$ from the starting materials increases with an increase in the heating temperature and heating time. For the ceramic reaction involving $\mathrm{SrCO}_{3}$ and $\mathrm{SiO}_{2}$, the three-dimensional solidstate reaction model is considered. The formation of $\mathrm{Sr}_{2} \mathrm{SiO}_{4}$ is confirmed to be governed by a diffusion controlled mechanism via reaction kinetic isothermal analysis. The XRD patterns showed that the phosphors were composed of orthorhombic. The average crystallite size of the $\mathrm{Sr}_{2} \mathrm{SiO}_{4}$ phosphor is $22 \mathrm{~nm}$. From the emission spectra, the peaks at 589-593, 613-619 and $702 \mathrm{~nm}$ are due to radiative transitions from ${ }^{5} \mathrm{D}_{0} \rightarrow{ }^{7} \mathrm{~F}_{1},{ }^{5} \mathrm{D}_{0}$ $\rightarrow{ }^{7} \mathrm{~F}_{2},{ }^{5} \mathrm{D}_{0} \rightarrow{ }^{7} \mathrm{~F}_{4}$. The broad emission spectrum occurs at $612 \mathrm{~nm}$ due to transition ${ }^{5} \mathrm{D}_{0} \rightarrow{ }^{7} \mathrm{~F}_{4}$. The CIE coordinates for the $\mathrm{Eu}^{3+}$, doped $\mathrm{Sr}_{2} \mathrm{SiO}_{4}$ phosphors were $\mathrm{x}=0.64$ and $\mathrm{y}=0.33$ which is a promising phosphor host for use in white light emitting diodes.

\section{Acknowledgement}

We gratefully acknowledge the kind support of the management of ASC College, Bhalod, Dist. Jalgaon. Authors express their sincere thanks to Dr. K. V. R. Murthy, Faculty of Engineering and Technology, M. S. University, Baroda, for the measurement of Photoluminescence spectra of samples.

\section{References}

[1] Pradip Z. Zambare and O.H. Mahajan Invertis Journal of Science and Technology, 6(3), (2013), 150-154.

[2] Lim M A. Park J. K., Kim C. H., J. Mater Sci Lett, 22(2003), 1351-1353.

[3] Liu Jie, Lian Hongzhou, SUN Jiayue, Chem Lett, 34(10), (2005) 1340-1343.

[4] Zeng Q., Tanng H. Egoshi K., Appl Phys Lett, 88(051996) (2006), 1-3.

[5] Yang Zhimping, Liu Yufeng, Acta Phys Sin, 55(09) (2006) 4946-4950.

[6] J.S. Kim, P.E. Jeon, J.C. Choi, H.L. Park, Appl. Phys. Lett. 84 (2004) 2931-2933.

[7] H. Zhang, T. Horikawa, H. Hanzawa, A. Hamaguchi, K.I. Machida, J. Electrochem. Soc. 154 (2007) J59-J61.

[8] G. Blasse, P.E.Wanmaker, J. Vrugt, Philips Res. Rep. 23 (1968) 189-200.

[9] J.S. Yoo, S.H. Kim, W.T. Yoo, G.Y. Hong, K.P. Kim, J. Rowland, P.H. Holloway, J. Electrochem. Soc. 152 (2005) G382-G385.

[10] A. Nag, T.R.N. Kutty, J. Mater. Chem. 14 (2004) 1598-1604.

[11] J.K. Park, M.A. Lim, C.H. Kim, H.D. Park, J.T. Park, S.Y. Choi, Appl. Phys. Lett. 82 (2003) $683-685$.

[12] Pradip Z. Zambare, K. D. Girase, K. V. R. Murthy, O. H. Mahajan, Adv. Mat. Lett. 4(7), (2013), 577-581.

[13] J.S. Kim, J.Y. Kang, P.E. Jeon, J.C. Choi, H.L. Park, T.W. Kim, Jpn. J. Appl. Phys. 43 (2004) 989-992.

[14] QIAO Yanmin, ZHANG Xinbo, YE Xiao, CHEN Yan, GUO Hai. Journal of rare earths, 27, 323, (2009).

[15] I.M.Nagpure, Subhajit Saha, S.J. Dhoble, Journal of luminescence, 129, 898-905, (2009).

[16] Roshani Singh and S.J. Dhoble, Adv. Mat. Lett.,2 (2011) 341.

[17] Color Calculator version 2, software from Radiant Imaging, Inc, (2007).

[18] K.N. Shinde and S.J. Dhoble, Adv. Mat. Lett.,

IOSR Journal of Applied Physics (IOSR-JAP) is UGC approved Journal with Sl. No. 5010, Journal no. 49054.

Chaudhari Dilip B. "Synthesis and Optical properties of Eu3 doped Sr2SiO4 Phosphor for Solid State lighting applications ." IOSR Journal of Applied Physics (IOSR-JAP) 9.4 (2017): 37-41. 